\section{Ueber Einrichtung von Winterkuren in den schlesischen Kurorten.}

Vortrag, gehalten in ler Sitzıng des ersten balneologisclıen Congresses zII Berliı am 26. Januar.

Von

Dr. Paul Kolbe aus Reinerz.

Stützte inich niclıt das Vertrauen ouf eiue wahrlıaft gotte Sache, so würde ich als Arzt eines Kurortes, welcher wegen seines angeblich rauhen Klimas bis vor wenigen Jalıren so in Verrut war, dass man kaum im Juli ohne Bedenken seine Patienten dorthin senden konnte, es kauın wagen, vor Ihnen, neeine Herren, für Einrichtung von Winterkuren in den sclılesischen Gebirgsstädten zu plaidiren; doch es handelt sich dabei nur, alt hergebrachten Vorurtheilen entgegen zu treten und iclı kann das um so leicliter, als die moderne Klimatologie unter klimatischen Kurorten nicht mehr Orte versteht mit möglichst hohen, sondern mit möglichst constanten Temperaturgraden, Orte, deren reine und ruhige Luft den Patienten möglichst langen Aufenthalt in Freien gestattet. Die westlichen Thernalbäler Deutsclllands sind den schlesischen Bädern vorangeeilt; sie verschliessen nicht melır itıre Badezellen bei Eintritt des Winters, obwohl anch gegen sie das noch gegenwärtig weitverbreitete Vorurtheil bestelıt, dass es nit den warmen Bädern inı Winter, wenngleich mit grösster Vorsicht gebranclıt, lennoch eine gefährliche Sache sei. Und welchen Segen gewälırt nicht die dortige Winterkur den Patienten, deren Leiden einen sofortigen kurgebrauch nothwendig machen, Patienten, welche der Sommer an das Haus, an das Bett fesselt! Auch die schlesischen Bäder sind verpflichtet, für ihre Patienten besser als seither zu sorgen und es ist ein grosses Verdienst des schlesischen Bädertages, dass er in seinen letzten Sitzungen den Fragen näher getreten ist, olı die Einriclıtung von Winterkıren inı sclılesischen Gehirge wünschenswerth und nothwendior sei, und ob die Bäder auch des Winters ihre Heilkraft entwickeln können. Für die Thermalbäder Landeck und Warmbrunn beantworten sich diese Fragen nach den in den zahlreichen Schriften über die rlıeinischen Thermalluäder ausgesprochenen Ansichten und ist Warmbrunn bereit, seine für Winterkur passenden Bade-, Wohnund Gesellschaftszimmer dein Publikum zur Disposition zu stellen.

Was die andern kurorte betrifft, deren Hauptindication chronische Lungenkrankheiten sind, so bedarf es wohl keines weitern Beweises, wie der Besitz inländischer klimatischer Winterkurorte für die norddeutschen Aerzte und Patienten gleich wünschenswerth, gleich notliwendig ist. Ich will hier nicht des Weiteren die Publicationen von Starke und Friedmıan n erörtern, welche siclı in der Berl. klin. Wochenschr. finden und in denen mit aller Schärfe betont wird, dass es für einen grossen Theil der in den italienischen Winterstationen befindlichen Lungenkranken weit vortheilhafter gewesen wäre, in ihrer norddeutschen Heimath zu bleiben, aber ich spreche hier die feste Ueberzeugung aus, dass der rege Eifer, nit welchem gegenwärtig die balneologischen Studien getrieben werden, uns schon in den nächsten Jahren von den Vorurtleilen befreien wird, welche wir als ächte Deutsche zu Gunsten ausländischer, speciell der italienischen kurorte hegen und pflegen. - Doch sei das, wie es wolle; gewiss nur wenige Procente seiner Patienten ist der Arzt in der Lage, nach dem Süden zu schicken; ball hindert der leidige Mangel an Geld den längeren Aufenthalt in südlichen Klimaten, bald macht der körperliche Zustand des Patienten die weite Reise unmöglich, bald end- lich scheuen Patient und Angelıörige die längere Trennung durch ausgedehnte Ländergebiete. Was soll der Arzt mit Patienten dieser Art beginnen, wenn er den Beginn des phthisischen Processes in October entdeckt? Er muss sie 7 Monate lang anf das warten lassen, was nach den lieutigen Anschauungen der Wissenschaft das einzig sichere Mittel gegen Phthlisis ist, und während dieser Zeit hat er die schöne und doch so traurige Gelegenheit, zu beolachten, wie unter denı Einfluss des Winters der norddeutschen Ebene mit den täglichen bedentenden Temperatırschwankungen, nit den läufigen Nebelı, unter dem Einfluss der init Ranch, Russ und Miasmen aller Art geschwängerten Stadtluft, unter deın Einflusse von Gesellschaften, Vergnügıngen aller Art, Geschäften, denen sein Patient, so lange er zu Haus ist, sich nicht entzielen kann oder mag, die Veränderıngen in deı Lungen bis zı aussichtslosen Stadien vorrücken.

Die zweite Frage, ob die schlesisclıen Gehirgshäaler als Winterkurorte Lungenkranken Nutzen bringen hönneı, kann ich vor alleı theoretisclıen Erörterungen, auf die langjährige Erfahrung meiner im Gebirge practicirenden Collegen gestützt, ohne Rückhalt bejahen. Brehnıer ist sich nach neunjähriger Praxis in seiner Kuranstalt zı Görhersolorf desseı sicher, dass im Winter mindestens ebenso gute Resultate erzielt werden als im Sommer, dass die Lungenkranken den Winter im schlesischen Gehirge ganz vorzüglich vertragen, dass endlich die intercurrirenden Bronchialund Larynxcatarrhe im Winter weit seltener zur Beobichtung kommen

All den klinatischen Winterkurort stellt die moderne Klimatologie, wie ich bereits erwähnt habe, niclıt nıehr die Forlerung möglichst südlicher Lage und hoher Wärne, sondern verlangt von thın eine constante Temperatur, eine reine, ozonreiche Luft, eine gegen lieftige Windstrïmulngen geschiitzte Lage in inmuner Höhe, endlich für Winterkuren geeignete Wohnungen und kurbäuser. Diesen Forderungen können die schlesischen Gebirgsbäder vollkommen gerecht werdeu. Sie befinden siclı in immuner Höhe, Reinerz z. B. 1780 Fuss über dem Meeresspiegel, in gegen leftige Windströmungen geschützter Lage, da die sie umgebenden Berge sich bis zu einer Höhe von 2500 bis 3300 Fuss erheben. Für eine reine, ozonreiche Luft leistel die grossen Waldcomplexe die beste Garantie; es belaufen sich die Reimerzer Tannen- und Fichtenwaldıngen auf 12 bis 13000 Hektar.

Was die Temperaturen anlangt, so bin ich nur in ler Lage, hier die in Reinerz beobachteten Zahlen wiederzugelen, loch glaube ich, dass sie von den in den Nachbarbädern beobachteten nicht sehr differiren werden. Für Reinerz liegt bereits ein bedeutendes Beobachtungsmaterial vor, welches seit 1867 voı Dr. Drescher, später von der neu eingerichteten nueteorologischen Station zusammengetragen worden ist. Es ergeben sich aus ilın als Durchschnittstemperatur für die Sommermonate 11,5 bis $13^{\circ}$ R. Das zehnjährige Mittel beträgt $12,34^{\circ}$ R. Für die Winterinonate ergeben sich für die Jahre $\mathbf{1 8 7 6}, \mathbf{7 7}, \mathbf{7 8}$ als inittlere Temperaturen $+9,41,+6,60$ und $5,99^{\circ} \mathrm{R}$.

Es ist hier nieht der Ort, die Temperatursclıwankungen der einzelnen und der aufeinander folgenden Tage in Zahlen alıszulrücken, docl kann ich versichern, dass in den Talıellen von Temperatırsprüngen Nichts zII entulecken ist, was leicht erklärlich ist, la die rauhen, die Lnft schnell abkühlenden Windströmıngen weren der hohen Berge hier weit später zur Geltung kommen könnell als in der Ebne. Der Winter in unserm Gebirge interscheidet sich ron dem des Flachlandes durcl seine Gleichmässigkeit; der Sclınee, welchen der Novenıber nnd Dezember uns bringt, bleiht unser trener Gast, bis ihn die schon loochstehende Aprilsonne in rasch ansch wellendell Geljirgsbächen vertreibt; wir vermissen lierzlich gern die verfrühten Frühlingstage, welche sich die Ebene durch nasskaltes Wetter uud Thauwind erkauft, um uns bald darauf wieller durch Temperaturdifferenzen bis $-6^{\circ} \mathrm{R}$. zu übertreflen. Mlehr als $-18^{\circ} \mathrm{R}$. sind bei uns seit 12 Jahren nicht beobachtet worden, während die Ebne Temperaturen bis $7.0-\mathbf{2 2}^{\circ} \mathbf{R}$. 7.u verzeichnen hatte. - Die Zahl der Nebeltage ist les Winters bei uns bedeutend geringer als in Flachlande. Die ombrometrischen Mlessungen ergeben, dass es durchschnittliclı 40,5 Stunden während eines der Wintermonate regnete oder schneite. Während der 7 Wintermonate 1878 regnete und schneite es in Ganzen 270 Stunden.

Der mittlere Baroneterstand ist für die Wintermonate 1876, 77 und 78: 314,00, 311,00 und 314,00. Die ozonometrischen Messungen ergeben für die Wintermonate genannter Jahre als Mittel die Zahlen $\mathbf{7}$, 8 und 8,72

Was die für Winterkuren nothwendigen Baulichkeiten betriff, so kann ich nur von Reinerz, welches den übrigen Bädern in der Einrichtung der Winterkur vorangehen will, berichten, dass die dortige Verwaltıng lıoff, bis $\mathbf{1 8 8 1}$ die umfangreichen und geschmackvollen hurgebäude vollkommen ausseführt zu haben; sie werden Forderungen, welche man an Sanatorien stellt, durchaus entsprechen. -

Zum Schluss möthte ich mich noch gegen den Verdacht verwahren, hier pro domo geredet zu haben; nicht aus pekuniärem Interesse errichtet Reinerz eine Winterkuranstalt - und nach aller Berechnung können die Auslagen wohl kaunı durch die Einnahmen gedeckt werden - sondern aus 
rein humanem und sanitärem Interesse, in dem Bestreben, das Bad vou dem Standpunkte der einfachen Sommerfrische, wo die leichteren Patienten die von alter Gewolnhlseit vorgescliriebenen 4 oder 6 Wochen unr zu Ausflägen in das Gebirge benützen, während die schwerer Erlirankten unter allen Mängeln und Lebeln überfüllter Bäder zu leiden haben, zu dem Standpunkte eines wirkliehen Heilortes für Lungenkranke zu erleben, ein Bestreben, welchem hoffentlich recht bald auch die ülorigen schlesischen Gebirgsbäder nacheifern werden. 